\title{
Behavior of the black flying fox, Pteropus alecto (Chiroptera: Pteropodidae) in cages
}

\author{
TILTJE ANDRETHA RANSALELEH ${ }^{1, \vartheta}$, INDYAH WAHYUNI ${ }^{1}$, MARTHA KAWATU ${ }^{1}$, \\ MEIS JACINTA NANGOY ${ }^{1}$, SIGIT WIANTORO ${ }^{2}$ \\ ${ }^{1}$ Faculty of Animal Science, Universitas Sam Ratulangi. J1. Bahu, Malalayang, Manado 95115, North Sulawesi, Indonesia. Tel.: +62-431-863886, \\ "email: taransaleleh@unsrat.ac.id \\ ${ }^{2}$ Museum Zoologium Bogoriense, Research Center for Biology, National Research and Innovation Agency. J1. Raya Jakarta-Bogor Km.46, Cibinong, \\ Bogor 16911, West Java, Indonesia
}

Manuscript received: 20 October 2021. Revision accepted: 30 December 2021.

\begin{abstract}
Ransaleleh TA, Wahyuni I, Kawatu M, Nangoy MJ, Wiantoro S. 2021. Behavior of the black flying fox, Pteropus alecto (Chiroptera: Pteropodidae) in cages. Biodiversitas 22: 5657-5665. Hunting and illegal trading have become a common thread for the black flying fox in Sulawesi, Indonesia. However, information on its biology and behavior as a baseline for conservation and management program is still lacking. Therefore, this study aims to examine the behavioral activities of black flying fox, Pteropus alecto (Temminck, 1837) kept in cages through direct observation. The results showed that feeding was carried out by descending to the bottom of the cage before picking up fruits with the mouth and wings. Furthermore, the time associated with this process ranged from 06.01 to 10.00 , while agonistic behavior performed using claws and wings took place from 10.01 to 14.00 in the daytime and 22.01 to 02.00 at night. Grooming was carried out using the tongue and wings, from 14.01 to 18.00 during the day and 22.01 to 02.00 during the night. Subsequently, the bats slept by perching with the eyes closed and the whole body wrapped with the wings from 02.01 to 10.00 , while locomotion and stationary behaviors were performed by perching with eyes open and flying around the cage with the wings spread apart from 10.01 to 14.00 during the day and 22.01 to 02.00 at night. The percentage of day and night behavior activities consist of agonistic $0.12 \%$, grooming $6.14 \%$, eating $19.36 \%$, sleeping $56.33 \%$, and stationary and locomotive $17.76 \%$. The results improve the understanding of $P$. alecto's daily activities in the cage which are difficult to observe in the wild and provide insight for conservation and wildlife management. Furthermore, information from this study is useful for future bat captivity programs.
\end{abstract}

Keywords: Activity, behavior, day, night, flying fox, Pteropus alecto

\section{INTRODUCTION}

Bats play an ecological role in maintaining forest diversity due to their function as seed dispersers (Seltzer et al. 2013; Deshpande and Kelkar 2015; Lartey et al. 2016) and pollinators of plants with high economic value such as durian (Aziz et al. 2017; Lim et al. 2018; Sritongchuay et al. 2019; Tremlett et al. 2020; Low et al. 2021; Muhammad et al. 2021). However, they are hunted and consumed in some communities (Scheffers et al. 2012; Ransaleleh et al. 2013; Suwannorang and Schuler 2016) due to their medicinal properties (Mildenstein 2016; Aziz et al. 2017; Low et al. 2021; Rocha et al. 2021), and the ability to increase stamina (Suwannarong et al. 2020).

In North Sulawesi, bats meat particularly flying foxes such as Acerodon celebensis (Peters, 1867) and Pteropus alecto (Temminck, 1837), are imported and traded in traditional markets for consumption (Sheherazale and Tsang 2015; Latinne et al. 2020; Ransaleleh et al. 2020). Based on a survey conducted during the COVID-19 pandemic, frozen flying foxes are sold in some supermarkets in cities like Manado, Tomohon, and Amurang, of North Sulawesi, Indonesia. Meanwhile, $P$. alecto is one of the preferred species for consumption (Ruba et al. 2016) due to its large body size with the percentage of carcass ranging from $45.37 \%$ to $54.07 \%$ of the total body weight (Ransaleleh et al. 2014), but its high demand causes uncontrollable hunting. According to the IUCN Red List category and criteria, $P$. alecto is categorized as Least Concern, indicating a species at low risk. However, the continuous hunting of this species with a long reproductive cycle, once a year, with only one pup per birth might lead to a severe population decline.

The rampant hunting and selling of bats depict that the community's understandilng of its role in the ecosystem is limited, which might lead to extinction. Therefore, there is a need to determine its sustainability through approaches related to the legal status of fruit-eating bats (Maulany et al. 2021), socialization in human life, and conservation efforts (Frick et al. 2019). The behavioral activities such as agonistic, grooming, sleeping, feeding, stationary, and locomotion provide essential information for its conservation and management (Markus and Blackshaw 2002; Ter-Hofstede and Fenton 2005; Connell et al. 2006). However, there is a lack of information and study on flying fox bats in Indonesia. The behavioral activities exhibited by $P$. alecto in its habitat were reported 19 years ago (Markus 2002; Markus and Blackshaw 2002) and were observed during the day. This is because a complete observation of flying fox behavior covering day and night activities in the habitat is difficult, consequently, observation in captivity is one of the suggested methods. 
Therefore, this study aims to observe the behavioral activities of $P$. alecto in cages during the day and at night. Aside from supporting an effective wildlife management program, this study also provides information to develop bats captivity which has not been carried out previously. Captivity and domestication are proposed as solutions to increase bats population, a source for wildlife utilization, and overcome the threats such as hunting in the natural habitat.

\section{MATERIALS AND METHODS}

\section{Study area}

This study was carried out in Neighborhood V (Lingkungan $V$ ) of Wanea Village, Manado, North Sulawesi, Indonesia with coordinates $1^{\circ} 27^{\prime} 39^{\prime \prime} \mathrm{N}$ and $124^{\circ} 50^{\prime} 33^{\prime \prime}$ E (Figure 1) for four months, from April to July 2021. A total of 9 P.alecto species consisting of two adult males, three juveniles, two females that had never given birth, and two lactating individuals were used. All subjects were kept in the 2.5-meter cage made of tasso and ram wire, with a size of $3 \times 1.5 \times 1.5$ meters $(\mathrm{LxWxH})$. Meanwhile, the adult subjects have been the wildlife market and placed in the cage since 2011. In 2020, they were moved from the old cage made from wood to a new one, while the sub-adults and juveniles were born in this new cage in 2020 .

\section{Procedures}

The preliminary observation was conducted to determine the time and type of behavioral activities exhibited in the cage. During the day, the subjects were observed from 06.01 to $10.00,10.01$ to $14.00,14.01$ to 18.00 , and at night, from 18.01 to $22.00,22.01$ to 02.00 , 02.00 to 06.00 . This was carried out from March to July 2021 and the types of behaviors observed include agonistic, grooming, feeding, sleeping, and other activities such as locomotion and stationery which were directly observed using observation sheets, CCTV, and cameras. The recorded and documented data were the duration descriptions of each observed behavioral activity. Furthermore, the recorded activities from the CCTV cameras were re-played, examined, and recorded in the observation sheets. Given that there is no previous similar study, data and information collection were set consistently for every two days during the day and at night, from 06.01 to 06.01 for 24 hours throughout this study (Markus and Blackshaw 2002). Furthermore, environmental conditions including the air temperature and humidity were also recorded periodically, during the day $(06.00-10.00,10.00-$ $14.00,14.00-18.00)$ and at night (18.00-22.00, 22.00-02.00, 02.00-06.00). During the day, data collection was carried out by two persons, while at night, it was performed by three persons to avoid bias observation since bats as nocturnal animals are more active during the night.

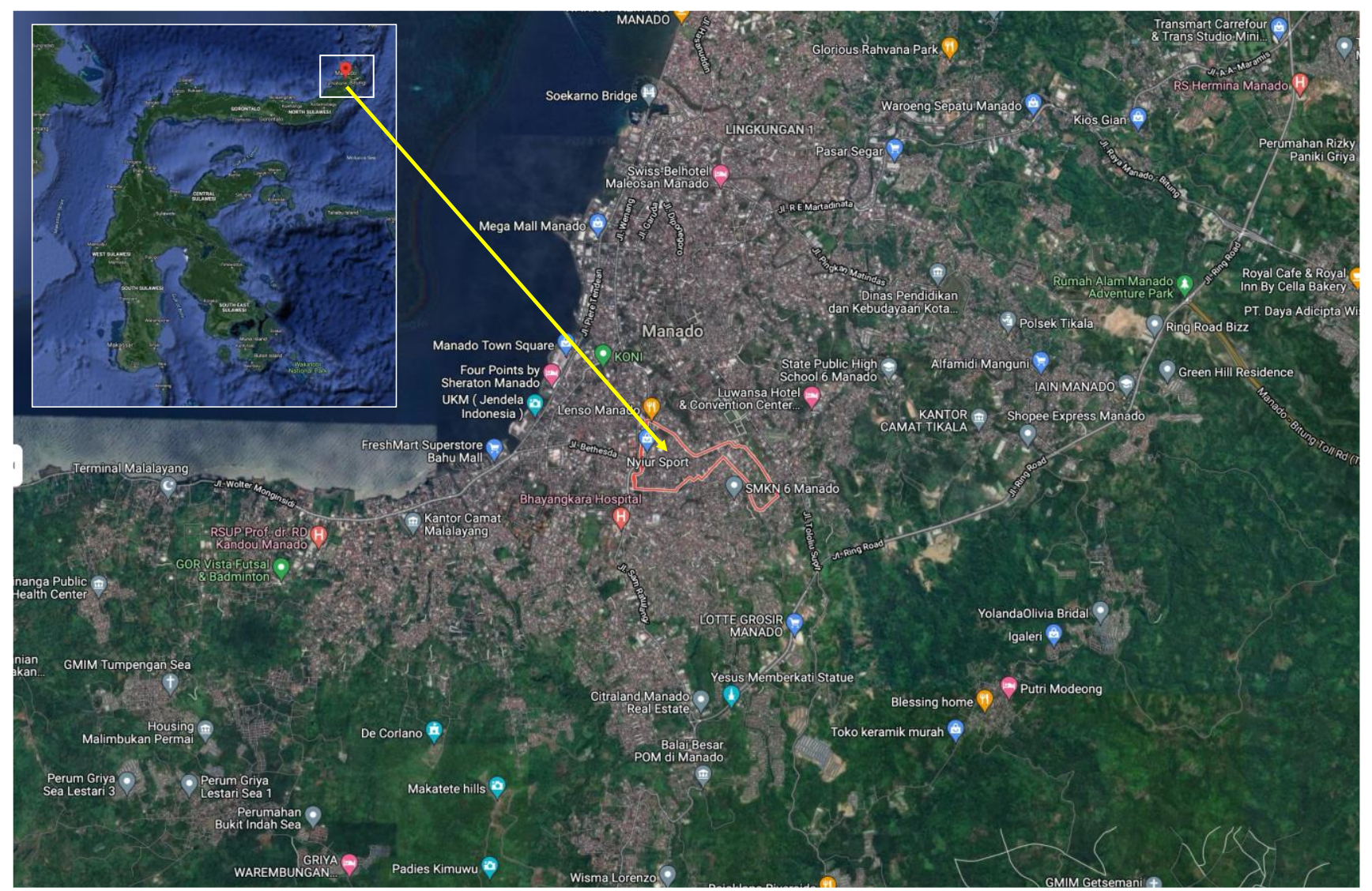

Figure 1. The study area was in the Neighborhood V of Wanea Village, Manado, North Sulawesi, Indonesia with coordinates of $1^{\circ} 27^{\prime} 39^{\prime \prime} \mathrm{N}, 124^{\circ} 50^{\prime} 33^{\prime \prime} \mathrm{E}$ 


\section{Data analysis}

The descriptive data on $P$. alecto behavior including the length of activities were then tabulated, averaged, and presented as a percentage narrative form.

\section{RESULTS AND DISCUSSION}

\section{Feeding behavior of Pteropus alecto in cages}

Before feeding, all bats perched near the cage door while making repeated sounds, then after the food was spread on the floor, each crawled down quickly to grab some with the mouth and wings. Afterward, they chewed the food and also held some with the toes. Other individuals fed with the legs tied together with wires, and the bodies leaning on the cage floor near the food. It was observed that some bats did not take food from the floor, rather from those that were perched, such as bats with cubs. Based on the observed behavioral descriptions, first, the mothers crawled to the bottom to get food while holding the cubs, returned to perch, as well as chewed and licked the liquid that came out of their mouth. Second, the cubs were released to perch separately, while the mothers went to the bottom of the cage to get food and returned to close to the cubs. The food was chewed severally, then the waste in the form of dietary fiber was expelled, and it was noticed that the subjects rarely drank. The feeding behavior of bats in cages is shown in Figure 2.

The feeding behavior of $P$. alecto species in cages was similar to others in the natural habitats. Still, the location, fruit type, feeding method, form of food served, and availability were different. Papaya (Carica papaya) was chosen as the primary type of food based on the previous observations. The preliminary examination showed that the subjects tend to choose chopped papaya compared to other provided fruits such as guava, water apple, and banana hung in the cage roof. Chopped papaya was scattered around the cage to give more options for the bats and avoid fighting. Markus and Blackshaw (2002) reported that bats' feeding behavior in the habitat includes chewing, licking, throwing food, and drinking water. Meanwhile, chewing produces juice extract, and the ability of the cubs to lick the mother's mouth is an act of introducing adult food (Dumont and O'neal 2004). The results illustrate that the bats in cages show similar feeding behavior with others in natural habitats, as Markus and Blackshaw (2002) mentioned. Still, it differs concerning food availability and sources. In this study, the feed was always prepared in the cage, while wild bats needed forage to obtain food.

Bats are nocturnal animals, hence, they are active during the night and spend most of the day for rest and sleeping. Consequently, ad libitum feeding was chosen in this study with most of the fruit being prepared at 18.00. The feeding duration was recorded from afternoon till evening, although this activity usually occurs from 18.01 to 22.00 , and it took a long time, relatively $11161.4 \pm 479.4$ seconds. However, there are no reports on the feeding time and duration, both in the natural habitat and cage. The observations showed that this attribute tends to change when they are not fed at night. Furthermore, when the subjects were not provided with sufficient food (full at night), they were bound not to eat during the day, irrespective of its availability in the cage. Instead, they returned to take the leftover food in the late afternoon. This illustrates that the feeding time of the captive bats has changed to daytime. In contrast, food is not available on perches for subjects in the natural habitat, therefore, they fly far in search of other sources, and this affects the timing and patterns of the feeding behavior. Schloesing et al. (2020) reported that other flying fox species, $P$. lylei depend on experience, availability and quality of food sources, and familiarity with the habitat. Moreover, Choden et al. (2019) stated that these species fly over relatively 6.88 to $105 \mathrm{~km}$ at night to forage, while Welbergen (2008) reported that $P$. alecto species usually leave the perches in search of food starting from 17.30 to 18.00 . Similarly, $P$. poliocephalus foraging time is often in the evenings because it depends on the weather and the presence of predators (Welbergen 2006).

\section{Agonistic behavior of Pteropus alecto in cages}

The agonistic behavior of $P$. alecto species was exhibited when receiving food (fruits), about to mate, or awake. During the feeding procedure, the dominant ones chased and attacked the others with claws, culminating in a fight. The chased bats continue to dodge while aiming and picking up the fruits using the wings and perches far from the attacking one while eating. This behavior occurred repeatedly and stopped after they had all been fed. Meanwhile, during the mating process, the male bats initially approach one of the females while circling the perch and attacking its counterparts with the claws. The attacked one tends to counterattack, using its foot and claws, which occurred severally. The female also hits back at the target, while screaming and a fight ensues, it then tries to evade by moving from one place to another and wrapping the whole body with its wings. The subsequent observed agonistic behavior relates to the male bats approaching the female from behind and then hooking its 2 wings on the back while holding that of its target and biting the neck. The female makes a sound and tries to escape from its grip, leading to a fight. However, once released from the grip, they cover the entire body with the wings. Another observed behavior was the male approaching the target by licking its mouth, head, body, and vagina. The female occasionally produces sounds that cause the male to pause for a moment and then continues with licking the target's vagina while circling the perched position and grabbing from behind, which leads to copulation. The last observed activity is a fistfight that only occurs briefly. Furthermore, when bats are awake, one often moves and scratches others next to it, which reacts by making a sound and clawing back at the attacker. The description of the agonistic behavior of $P$. alecto in cages is shown in Figure 3.

There are no scientific reports related to the agonistic behavior of $P$. alecto species during feeding in the habitat. However, the mating season which was suggested to be from February to April (Markus and Blackshaw 2002), is similar to the bats in captivity. Markus and Blackshaw (2002) reported that this behavior in the habitat maintains 
roost areas during the mating season. In addition, the male bats usually attack others to defend their partners, this behavior was also recorded in other species of flying fox, $P$. poliochalus which chases and fights each other using wings and teeth to protect individual territory (Welbergen 2011).

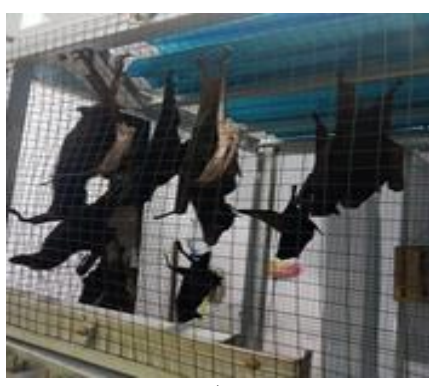

A

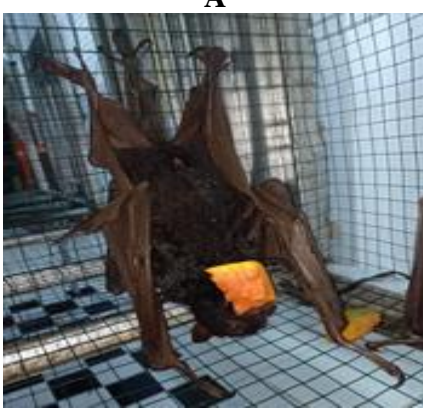

E

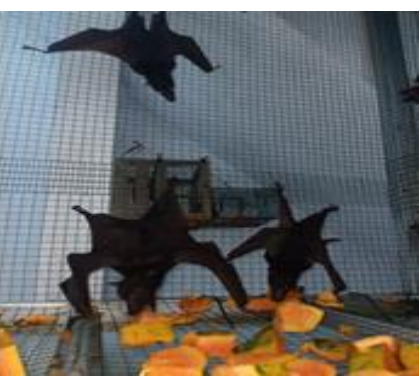

B

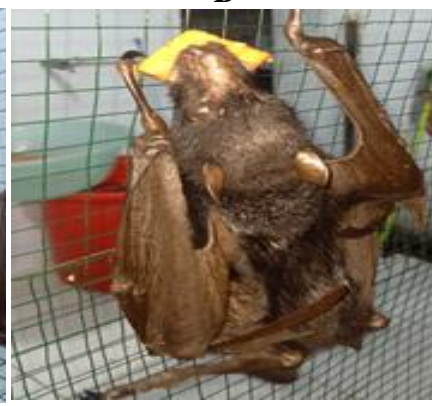

$\mathbf{F}$
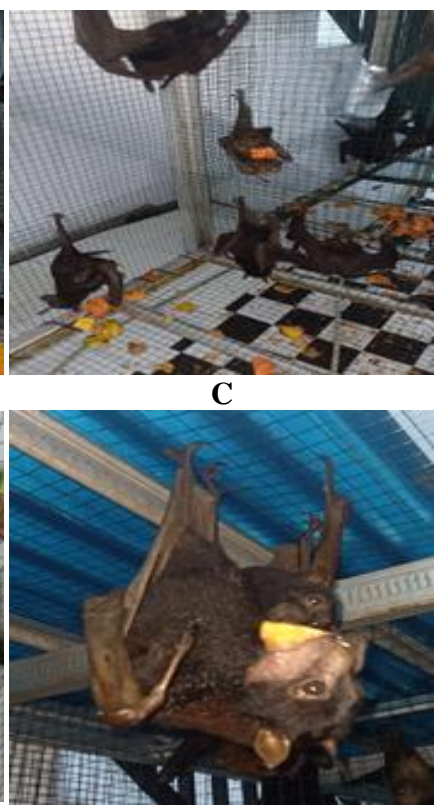

G

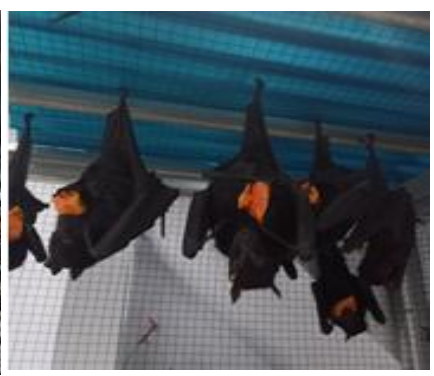

D

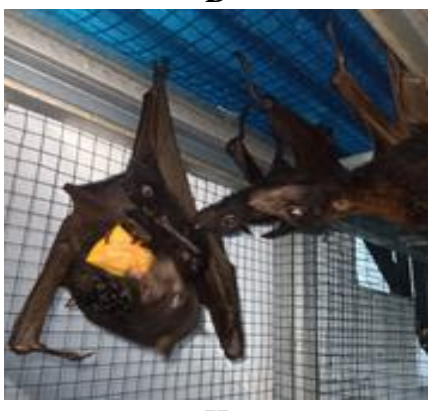

$\mathbf{H}$

Figure 2. Description of feeding behavior of Pteropus alecto in the cage. A. perch close to the cage door before feeding time, B. take the food with the mouth, C. eating with physical distancing between one individual to the others, D. eating while hanging in the cage roof, E. eating close to the cage floor, F. bite the fruit and move back to the perch site, G. feeding the infant, H. grab (steal) the food from the other individuals

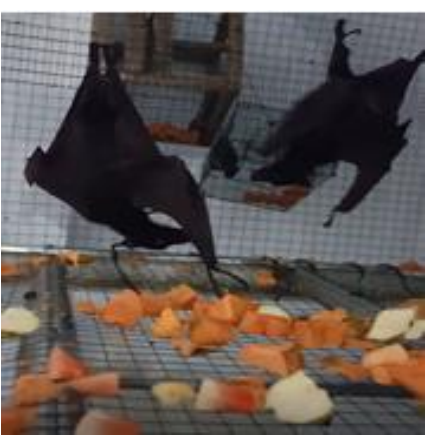

A

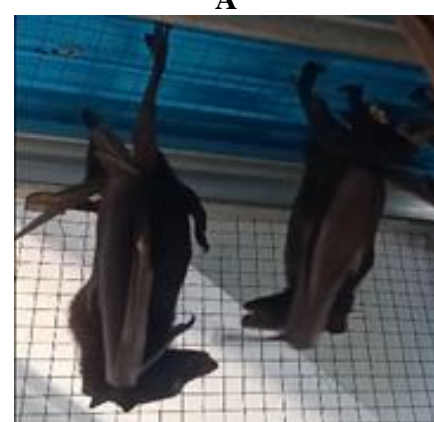

$\mathbf{E}$

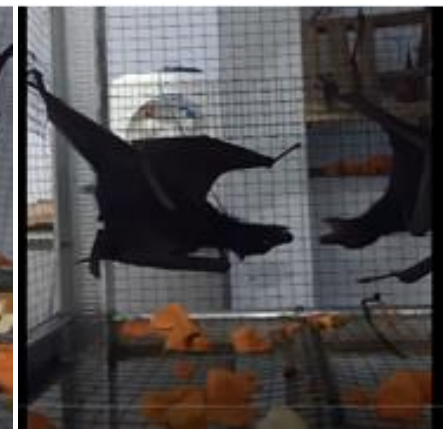

B

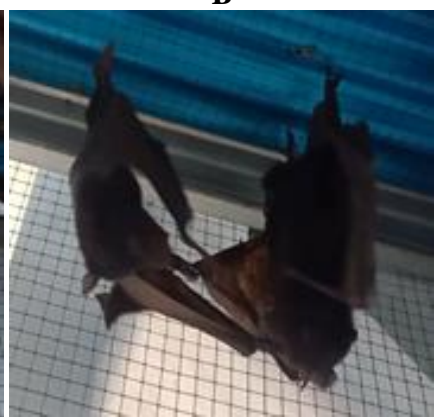

$\mathbf{F}$

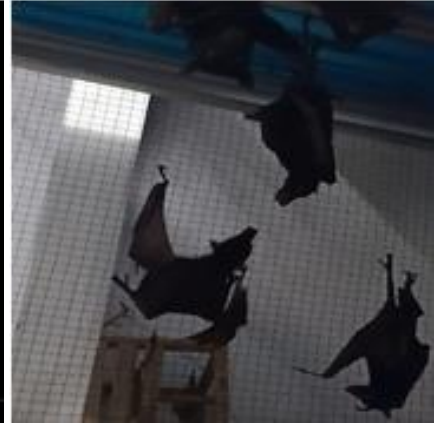

C

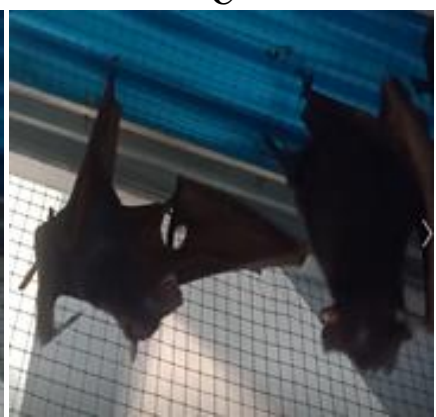

$\mathbf{G}$

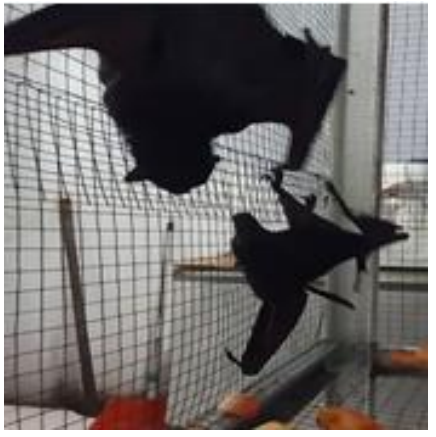

D

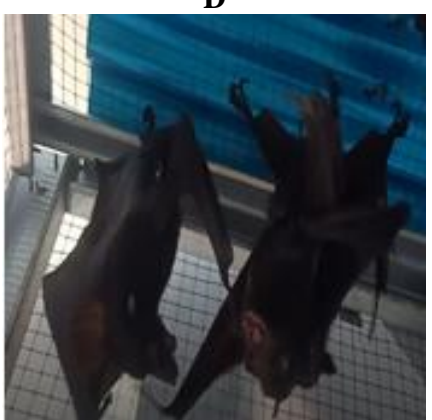

$\mathbf{H}$

Figure 3. Description of the agonistic behavior of Pteropus alecto in the cage. A. chasing other individuals, B. fighting over the food, C. attacking with the wings which move down to take the fruit, D. fighting on the floor, E. male moving closer to female, F. male attack female with the wing thumb, G. male and female attack each other, H. male embrace and bite the female's neck 
The agonistic behavior of $P$. alecto associated with the males trying to mate with the females was observed during the day and at night. During the day, it often occurs from 10.01 to $14-00$ for $15.7 \pm 9.1$ seconds, while at night, it is usually from 22.01 to 02.00 and lasts for $28.2 \pm 18.2$ seconds. Based on the observations, the males actively attacked the females from March to early April, while it rarely happened from May to July. However, the agonistic activity recorded in this study is different from that observed in the habitat due to the struggle to perch compared to the cage. There are no previous reports on the agonistic activity of $P$. alecto in the natural habitats both during the day and night. Markus (2002) reported that initially, these bats fly in the afternoon, mark tree branches by rubbing the necks and chests during the day, and the agonistic activity occurs once they return to perch on the tree in the morning. Moreover, it was observed that resident bats who own and permanently stay on the roost make sounds, chase, and fight non-resident ones which perch on the marked tree branches, and they, in turn, fly away within a duration $16.5 \pm 6.3$ seconds. Furthermore, the agonistic behavior during the mating season was relatively poor in the natural habitat due to the uneven sex ratio distribution that is, the number of adult females was more significant than the males. The results also showed that the agonistic activity of captive bats usually occurs during the day and at night. Therefore, in terms of breeding, there is a need to pay serious attention to the duration of feeding the cubs and the ratio of males to females namely the number of males in one group. This is because, during this season, male bats and breastfeeding mothers are usually active.

\section{Grooming behavior of Pteropus alecto in cages}

Grooming behavior is a treatment or effort to rid oneself of food remnants and oil from the skin glands (Markus and Blackshaw 2002). Based on the observation, all individuals, including the mothers and the cubs, nurtured themselves using the tongues, feet, toes, and claws. These were also used to scratch the face, head, teeth, back, neck, and ears. Sometimes the toes were slowly inserted into the ear canal, but when in a perched position, the tongue is repeatedly and rapidly used to lick the front of the body, starting from the abdomen, chest, genitals, and wings. The stroking of the genitals by the males causes a penile erection without ejaculation. The grooming behavior of $P$. alecto in cages is shown in Figure 4.

During the observation process, grooming centered on the muzzle, face, and genitals was carried out in pairs. The males performed genital grooming on the females, while the mothers routinely nurtured the cubs, including hugging during breastfeeding. Also, the mothers lick the heads, necks, and backs repeatedly, but the front and back of the bodies, especially the muzzle are licked when hanging close to the mothers. The grooming behavior of $P$. alecto observed in this study was similar to the process followed in its natural habitat. Markus and Blackshaw (2002) reported that this species generally engages in wing, ear, infant, and genital grooming. Furthermore, Markus (2002) stated that penile grooming was mainly observed during the mating process in the natural habitat.

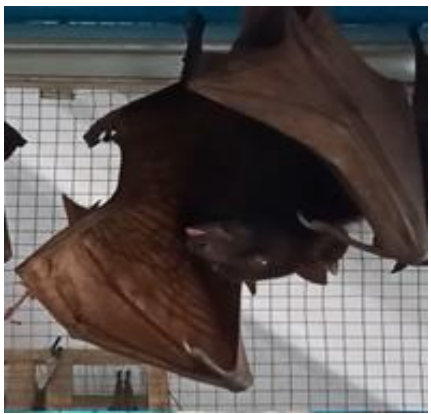

$\mathbf{A}$

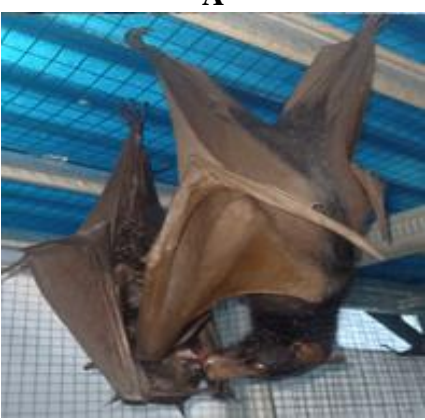

$\mathbf{E}$

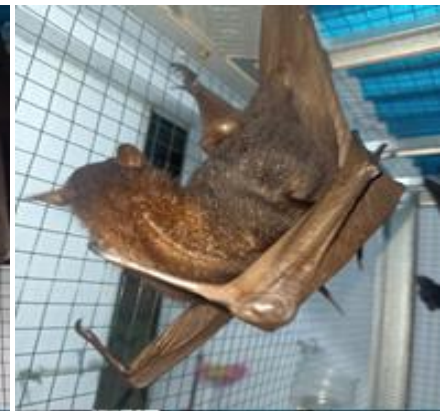

$\mathbf{B}$

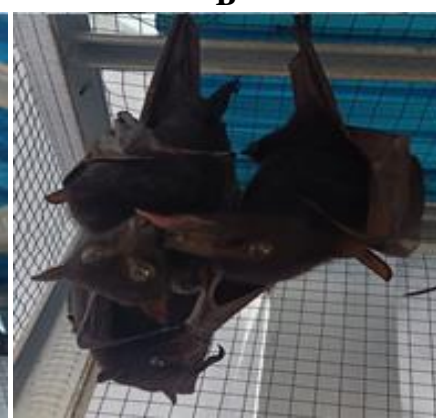

F

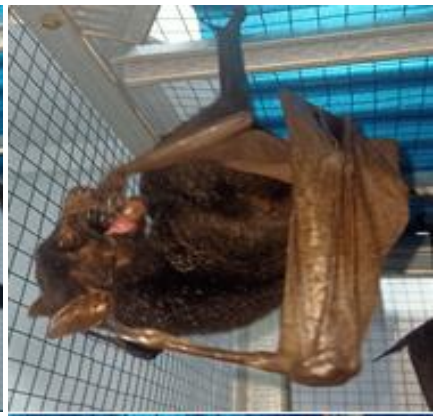

C

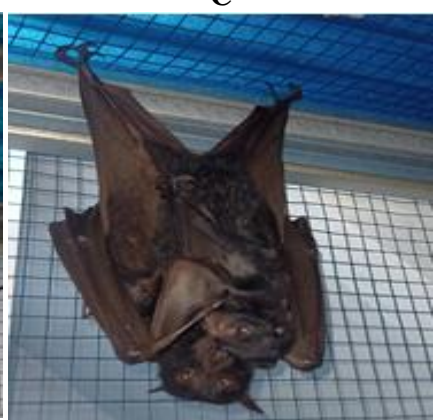

$\mathbf{G}$

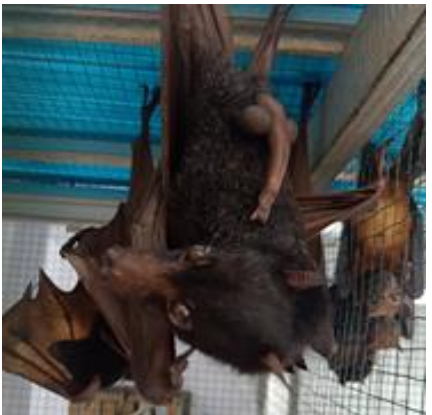

D

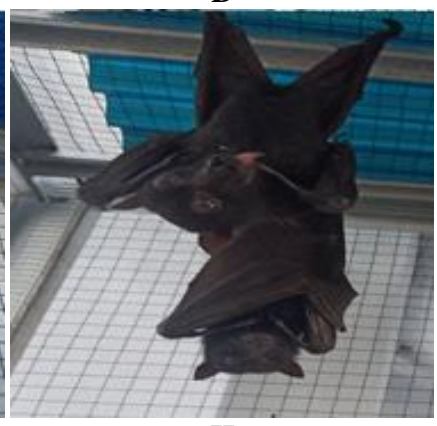

$\mathbf{H}$

Figure 4. Description of the grooming behavior of Pteropus alecto in the cage. A. wing auto grooming, B. mouth and ear auto grooming, C. male auto grooming caused the erection of its penis, D. muzzle allogrooming, E. vaginal allogrooming, F. mouth allogrooming, G. female grooming to its infant wing, H. female grooming to its infant's mouth 
The grooming process was conducted from morning to evening, during the day, it often occurs at 14.01 to 18.00 for $1216.7 \pm 179.5$ seconds, while at night, it takes place from 22.01 to 02.00 for $1930.9 \pm 387.8$ seconds. Grooming activities were frequently carried out during the day, when the subjects were awake, while at night, it was performed after they have been fed before locomotion and stationary activities. Meanwhile, nocturnal grooming activities in the natural habitat are reported rarely because bats emerge from the roost and fly to forage, while others in cages are fed. Markus and Blackshaw (2002) reported that P. alecto found in Indooroopilly and Norman Greeks Islands go out to forage in the late afternoons and return to the perches in the mornings. Furthermore, it was stated that this activity starts in the morning and is repeated throughout the day. This is consistent with Connell et al. (2006) which reported that grooming behavior in $P$. poliocephalus species mainly occurred in the mornings.

\section{Sleeping behavior of Pteropus alecto in cages}

The sleeping behavior of $P$. alecto was monitored throughout the study in two ways, first, they perched on one leg, with its wings wrapped around the body and the head tucked underneath. Second, they perched on two legs, with wings wrapped around the body, head pointing downwards, and eyes closed. However, the most common sleeping behavior is perching on one leg with the head tucked under the wings. The first behavior was generally exhibited during the cold weather, especially at night and in the mornings, and during rainfall with temperatures ranging from $24^{\circ} \mathrm{C}$ to $28^{\circ} \mathrm{C}$ with humidity of $98 \%$ to $80 \%$. The second was conducted during the hot season with temperatures ranging from $29^{\circ} \mathrm{C}$ to $32^{\circ} \mathrm{C}$ and $76 \%$ to $59 \%$ humidity. Based on the observations, the $P$. alecto's perching and sleeping positions did not change as the juvenile bats were close to the mothers, while the males were occasionally alone. This species usually wakes up when there are disturbances around the cage, such as people passing. This is proven by the movement of the heads and eyes while automatically shaking the ears, as shown in Figure 5. Based on the results, the sleeping behavior in the cage is similar to that of trees. Markus and Blackshaw (2002) reported that this species usually perches on both legs or one, with its wings wrapped throughout the body and the head tucked underneath. Furthermore, the weather regulates sleeping, behavioral activities, and when there is a disturbance, they react by directing the gaze. During hot weather, the bats open the wings, while in the cold season, it is folded, but when there is heavy rainfall, all activities are stopped. Additionally, the distribution of $P$. alecto perch in its natural habitat is consistent and does not change according to the existing group.

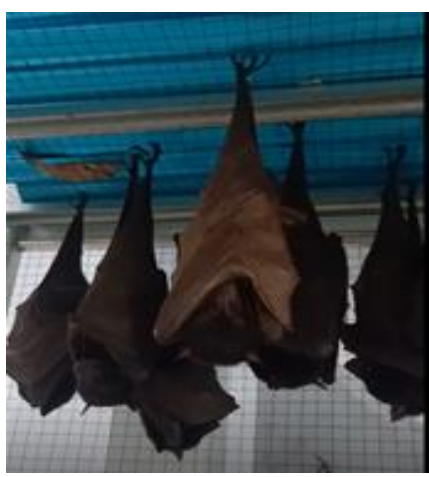

A

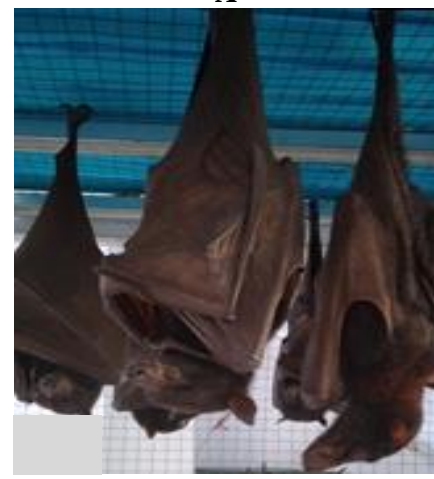

$\mathbf{E}$

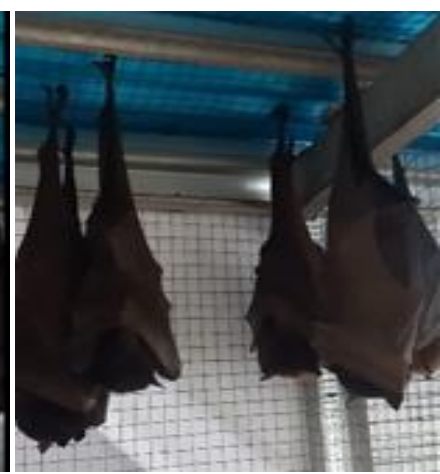

B

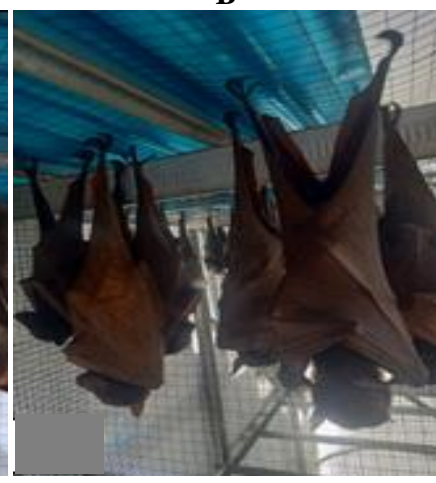

$\mathbf{F}$

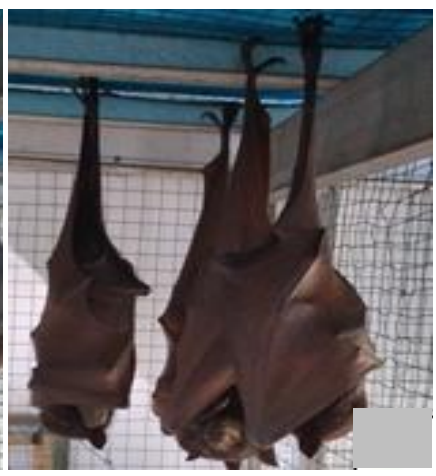

C

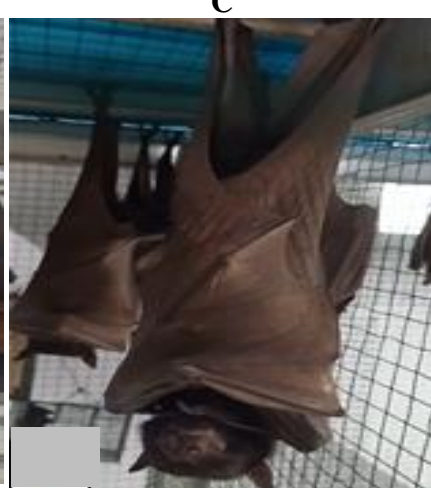

G

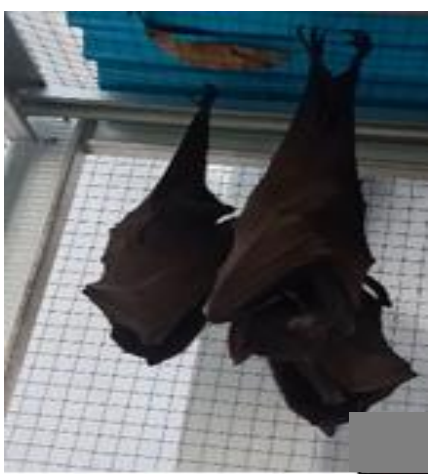

D

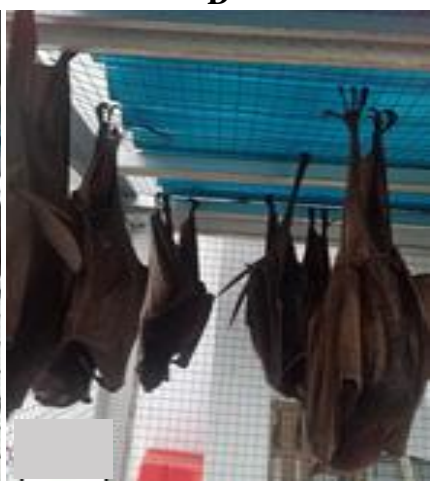

$\mathbf{H}$

Figure 5. Description of the sleeping behavior of Pteropus alecto in the cage. A. sleeping in a group, hanging with one leg and covering the head with the wing, B. sleeping in a sub-group, hanging with one leg and covering the head with the wing, C. sleeping alone, D. sleeping in back to back position, E. sleeping in a group, hanging with one leg and face the ground, F. sleeping in a sub-group, hanging with two leg and face the ground, G. sub-adult individual sleep close to the mother, H. sleep individual position 
The sleeping time for the subjects in the cage starts from 10.01 to 18.00 but they slept at night from 10.01 to 02.00 for $1270.6 \pm 235.6$ seconds and from 02.00 to 06.00 for $11513.7 \pm 345.2$ seconds. During this period, the bats were awake most of the time, performing certain activities such as feeding, grooming, agonistic, perching, and walking back and forth in the cage. Sleep during the day mainly was from 06.01 to 10.00 for $13967.9 \pm 560.9$ seconds, and from 10.01 to 14.00 for $12689.4 \pm 250.0$ seconds. In the afternoons from 14.01 to 18.00 , the sleeping time decreases to $9225.6 \pm 359.1$ seconds due to specific activities such as perching, grooming, agonistic, and feeding. Furthermore, most of the sleeping behavior was performed from 06.01 to 10.00 because the weather temperature ranged from $24^{\circ} \mathrm{C}$ to $29^{\circ} \mathrm{C}$. However, the time reduced towards noon because the temperature increased from approximately $29^{\circ} \mathrm{C}$ to $33^{\circ} \mathrm{C}$. At this time, bats perched while opening and flapping the wings. There is no information on the duration of sleep in the natural habitat at night because bats usually fly at that time in search of food. Compared to others in the cages, the food is generally available, therefore the time for foraging was used for sleeping and other activities. However, Markus and Blackshaw (2002) reported that the diurnal pattern of $P$. alecto is dominated by nesting, sleeping, grooming, and slight social activities, despite being awake for a long time during the day although primarily inactive. Also, Connell et al. (2006) reported that $P$. poliocephalus generally sleeps in the habitat during the day.

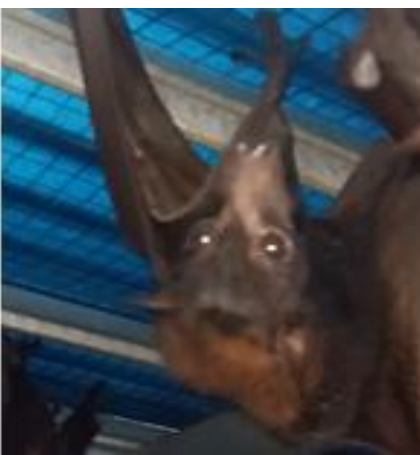

A

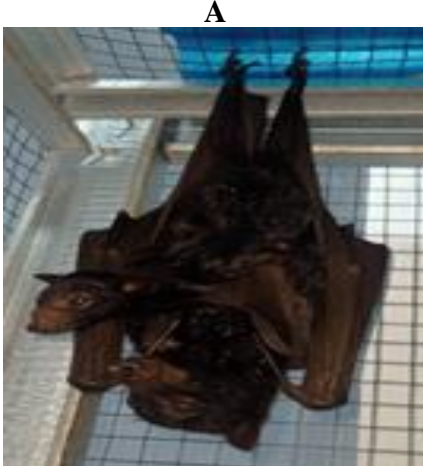

$\mathbf{E}$

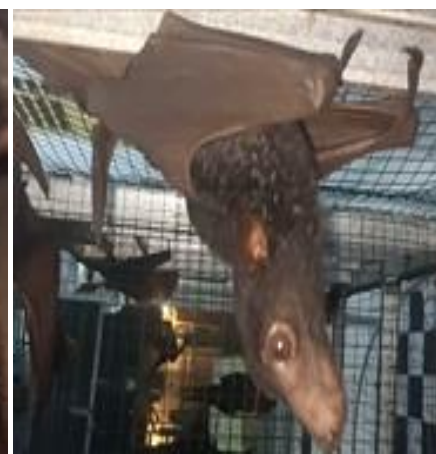

B

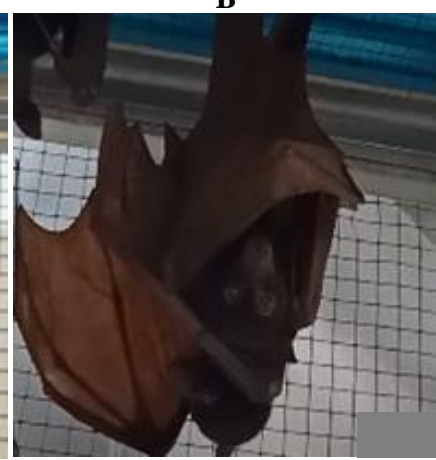

F

\section{Locomotion and stationary behavior of Pteropus alecto in cages}

The observed stationary behavior is as follows, first, the bats stretch by perching with their wings, spreading wide to the left, right, and forward, and then folding backward. Second, the wing fan is used by perching with part of its wings drooping while flapping slowly according to the movement of the head, ears, and eyes looking around the cage. The third is static flight performed by perching while the wings were flapped rapidly for a few seconds and then folded back. The first stationary behavior is usually performed during the day and at night, while the second is generally observed during the day when the weather is hot, and the third is at night. In general, cub and juvenile bats mainly practice static flight, who are still learning how to fly from the mother. The cubs were hooked to the mothers' legs on a ram wire, a moment later, they flapped the wings once and touched that of the infants, this activity was accomplished 2 to 3 times. Furthermore, the infants hugged the mothers again, and this activity was repeated until they could fly. The stationary behavior of the $P$. alecto in the natural habitat was also observed but in different places. The observed locomotive behavior includes the following, first, they perched on the two legs, the head lifted straight, the wings opened, and briefly flew around the cage. Second, the bats used both feet and claws to move back and forth on the porch, and crawl to the bottom, up and down through the cage rams in rapid motion. The description of this species' locomotion and stationary behavior in cages are shown in Figure 6.

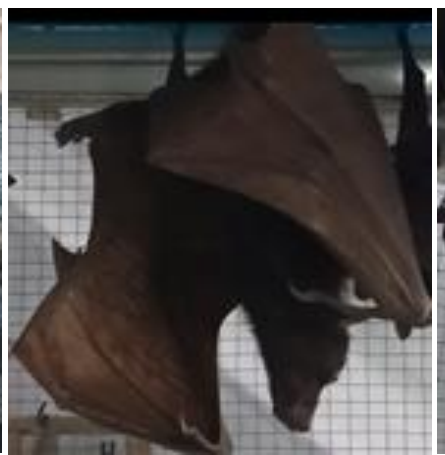

C

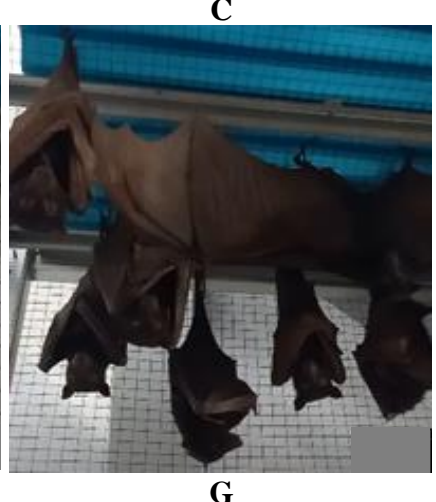

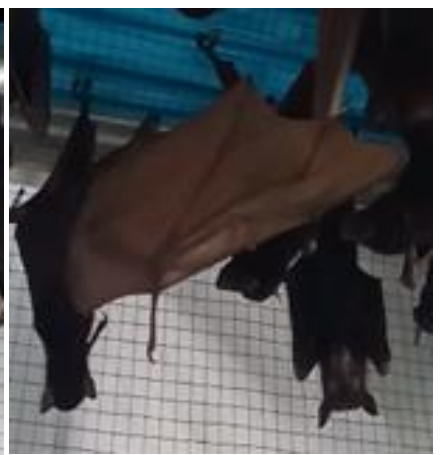

D

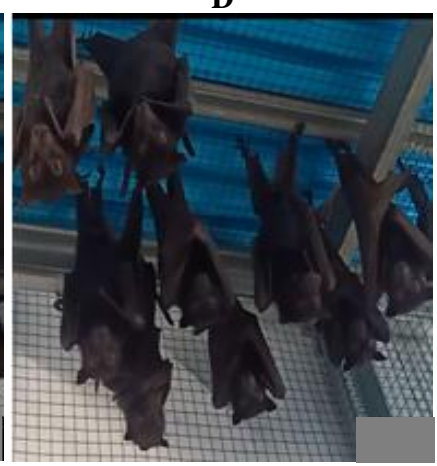

H

Figure 6. Description of locomotion and stationary behavior of Pteropus alecto in cages A. perch with eyes looking ahead, B. flight preparation, C. wings drooping while being fluttered, D. wings spread wide, E. infant learn to fly, F. mother opens wings behind the infant, G. juvenile opens wings while others are awake, H. perch while awake 
Table 1. Duration and percentage of day and night behavioral activity performed by Pteropus alecto in cages

\begin{tabular}{lcccccc}
\hline \multirow{2}{*}{ Behavior } & \multicolumn{2}{c}{ Day } & \multicolumn{2}{c}{ Night } & \multicolumn{2}{c}{ Total activity } \\
\cline { 2 - 7 } & Duration (second) & $\mathbf{( \% )}$ & Duration (second) & $\mathbf{( \% )}$ & Duration (second) & $(\%)$ \\
\hline Feeding & 2756,18 & 3,19 & 13970,21 & 16,17 & 16726,39 & 19,36 \\
Agonistic & 52,39 & 0,06 & 56,16 & 0,06 & 108,56 & 0,12 \\
Grooming & 2459,60 & 2,84 & 3088,19 & 3,57 & 5547,58 & 6,41 \\
Sleeping & 35882,35 & 41,53 & 12784,33 & 14,80 & 48666,68 & 56,33 \\
Stationary and locomotion & 2049,31 & 2,37 & 13300,91 & 15,39 & 15350,22 & 17,76 \\
Total & 43199,83 & 49,99 & 43199,82 & 49,99 & 86399,64 & 98,98 \\
\hline
\end{tabular}

The locomotion and stationary behavior generally do not involve physical contact with other bats in the cage, also, there are no differences between the captives and others in the natural habitat. Markus and Blackshaw (2002) reported that the flapping of wings and opening of mouths (pant) are actions engaged to cool the body during hot weather, while the spreading of wings wide (stretch) is performed to relax. Furthermore, the static flight was carried out to strengthen the wings and chest muscles in preparation for movement. In the natural habitat, $P$. alecto performs locomotion using both legs to hold branches, drooping wings that open on the left-right, back and forth, up-down, and briefly flying between the trees. Locomotion (moving) and stationary (remaining at a place) behavior is an activity that involves moving from one place to another without making any physical contact with other bats, by flapping, flying, and perching while covering all or part of the body with its wings while shaking the heads, and opening the eyes (Markus and Blackshaw 2002).

Locomotion and stationary activities of bats in cages were carried out during the day and at night. However, it was often performed at night from 10.01 to 02.00 for $9661.5 \pm 389.3$ seconds and from 02.01 to 06.00 for $7902.7 \pm 250.9$ seconds (Table 1). This is because bats are nocturnal animals and are primarily active at night as this time is used for foraging and returning to the perch in the early morning hours after getting food. In the cage, food is already available, therefore, they engage in other activities. However, bats' locomotion and stationary activities in cages at night were different from others performed during the day. At night, the bats move around quickly and actively perform motions, while during the day, they perch in a place, stay awake, and move when there is internal interference from others or external factors such as exposure to sunlight or people visiting the location around the cage. These activities are different compared to others in the natural habitat because, at night, they do not stay in the perch, except for cubs that are yet unable to fly. Markus and Blackshaw (2002) reported that the mothers leave the cubs at night, and they move by dragging or climbing branches and sometimes congregate to form small groups, wrestling at close range with the chests sticking together occasionally. Pulling wings without anyone dodging is interpreted as a play activity. Meanwhile, the locomotion and stationary activities of $P$. vampyrus bats in nature have been reported by Hengjan et al. (2017). They are primarily awake and engage in various practices during the day.

\section{Duration and percentage of day and night behavioral activity of Pteropus alecto in cages}

The activities of $P$. alecto were dominated by sleeping, feeding, stationary and locomotion, grooming, as well as agonistic behaviors at $56.33 \%, 19.36 \%, 17.76 \%, 6.41 \%$, and $0.12 \%$, respectively (Table 1 ). This indicates that $56.33 \%$ of bats did not engage in these practices, while $43.67 \%$ did. The dominant behavior during the day was sleeping, which was performed by $41.53 \%$, while at night $16.17 \%$ engaged in feeding. In contrast, the minor behavioral activities were agonistic during the day and night, while grooming, stationary, and locomotion were often carried out at night. There is no comparative literature on the percentage of day and night behavioral activities performed by captive $P$. alecto species and others in the natural habitat. The rate of daytime behavioral activities were observed in the Cynopterus sphinx and $P$. vampyrus species. Syamsi (2013) reported that $66.17 \%$ of C. sphinx slept during the day, followed by $21.09 \%$ that engaged in stationary and locomotion activities and $11.98 \%$ that participated in grooming. Furthermore, Hengjan et al. (2017) reported that the daytime activity of $P$. vampyrus species in the habitat was $53.1 \pm 13.9 \%$ grooming, $5.7 \pm 2.3 \%$ agonistic, $2.4 \pm 7 \%$ locomotion, and $2.3 \pm 1.6$ stationary. The percentage of agonistic behavior illustrates that the bats have adapted to the environment and food provided in the cage, consequently, fights that cause injuries and stress rarely occur. Therefore, the percentage of behavioral activities performed by the species in cages includes information and an initial description of the sustainable ex-situ breeding strategy. Based on the results, cage breeding is suggested as one of the solutions to provide a source for bats utilization and reduce threats such as hunting in the natural habitat. Moreover, it is expected that the critical behavior information obtained from flying fox in the cage is implemented for other bat species.

\section{ACKNOWLEDGEMENTS}

The authors are grateful to the Chancellor of Sam Ratulangi University through the Chair of the Institute for Research and Community Service for funding this study with the 2021 Unsrat Superior Basic Research (RDUU) scheme with contract number No. 235/UN12-13/LT/2021 and Assignment Letter No. 715/UN12.13/LT/2021. 


\section{REFERENCES}

Aziz SA, Clements GR, McConkey KR, Sritongchuay T, Pathil S, Yazid MNHA, Campos-Arceiz A, Forget P-M, Bumrungsri S. 2017. Pollination by the locally endangered island flying fox (Pteropus hypomelanus) enhances fruit production of the economically important durian (Durio zibethinus). Ecol Evol 7: 8670-8684. DOI:10.1002/ece3.3213. DOI: 10.1002/ECE3.3213

Connell KA, Munro U, Torpy FR. 2006. Daytime behaviour of the greyheaded flying fox Pteropus poliocephalus Temminck (Pteropodidae: Megachiroptera) at an autumn/winter roost. Aust Mammal 28 (1): 7 14. DOI: 10.1071/AM06002.

Choden K, Ravon S, Epstein JH, Hoem T, Furey N, Gely M, Jolivot A, Hul V, Neung C, Tran A, Cappelle J. 2019. Pteropus lylei primarily forages in residential areas in Kandal, Cambodia. Ecol Evol 9 (7): 4181-4191. DOI: 10.1002/ece3.5046.

Deshpande K, Kelkar N. 2015. How do fruit bat seed shadows benefit agroforestry? Insight from local perceptions in Kerala, India. Biotropica 47 (6): 654-659. DOI: 10.1111/BTP.12275.

Dumont RE, O’Neal R. 2004. Food hardness and feeding behavior in old world fruit bats (Pteropodidae). J Mammal 85 (1): 8-14. DOI: 10.1644/BOS-107.

Frick WF, Kingston T, Flanders J. 2019. A review of the threat and challenges to global bat conservation. Ann NY Acad Sci 1469 (1): 5 25. DOI: $10.1111 /$ NYAS.14045.

Hengjan Y, Pramono D, Takemae H, Kobayashi R, Iida K, Ando T, Supratikno, Basri C, Fitriana YS, Arifin EMZ, Ohmori Y, Maeda K, Agungpriyono S, Hondo E. 2017. Daytime behavior of Pteropus vampyrus in a natural habitat: The driver of viral transmission. $\mathrm{J}$ Vet Med Sci 79 (6): 1125-1133. DOI: 10.1292/JVMS.16-0643.

Lartey MA, Dechmann DKN, Wikelski M, Scharf AK, Farh J. 2016. Long-distance seed dispersal by straw-coloured fruit bats varies by season and landscape. Glob Ecol Conserv 7: 12-24. DOI 10.1016/J.GECCO.2016.03.005.

Latinne A, Saputro S, Kalengkongan J, Kowel CL, Gaghiwuc L, Ransaleleh TA, Nangoyd MJ, Wahyuni I, Kusumaningrum T, Safari D, Feferholtz Y, Li H, Hagan E, Miller M, Francisco L, Daszak P, Olival KJ, Pamungkas J. 2020. Characterizing and quantifying the wildlife trade network in Sulawesi, Indonesia. Glob Ecol Conserv 21: 1-18. DOI: 10.1016/J.GECCO.2019.E00887.

Lim VC, Ramli R, Bhassu S, Wilson JJ. 2018. Pollination implications of the diverse diet of tropical nectar-feeding bats roosting in an urban cave. Peer J 26 (6): 1-20. DOI: 10.7717/peerj.4572.

Low SY, Muhammad NHZ, Shukri SNSM, Samah AHA, Basri HZA, Shuhaimi MHM, Hamzah HN, Zahidin MA, Ariffin MSA, Mohamed NZ. 2021. Small pteropodid bats are important pollinator of durian in Terengganu, Malaysia. Pertanika J Trop Agric Sci 44 (3): 583-597. DOI: 10.47836/PJTAS.44.3.05

Low MR, Hoong WZ, Shen Z, Murugavel B, Mariner N, Paguntalan LM, Tanalgo K, Aung MM, Sheherazade, Bansa LA, Sritongchuay T, Preble JH, Aziz SA. 2021. Bane or blessing? Reviewing cultural values of bats across the Asia-Pacific Region. J Ethnobiol 41 (1): 1834. DOI: $10.2993 / 0278-0771-41.1 .18$

Markus N. 2002. Behaviour of the flying fox Pteropus alecto: 2 Territoriality and courtship. Acta Chiropterologica 4 (2): 153-166. DOI: $10.3161 / 001.004 .0204$

Markus N, Blackshow JK. 2002. Behavior of the black flaying fox Pteropus alecto: 1. An Ethogram of behavior and preliminary characterization of mother-infant interactions. Acta Chiropterologica 4 (2): 137-152. DOI: 10.3161/001.004.0203.

Maulany RI, Gautama RD, Dassir D, Hasri N. 2021. Capturing community behavior towards fruit bats conservation in South Sulawesi. IOP Conf Ser Earth Environ Sci 807: 1-16. DOI $10.1088 / 1755-1315 / 807 / 2 / 022029$.

Mildenstein T, Tanshi I, Racey PA. 2016. Exploitation of bats for bushmeat and medicine. In: Voigt C, Kingston T (eds.). Bats in the
Anthropocene-Conservation of Bats in a Changing World. Springer, New York. DOI: 10.1007/978-3-319-25220-9.

Muhammad NHZ, Low SY, Shukri SNSM, Samah AHA, Basri HZH, Shuhaimi MHM, Hamzah HN, Zahidin MA, Ariffin MSA, Zalipah MN. 2021. Flower visiting bats and durian trees: Special richness and population size. J Sustain Sci Manag 16 (5): 80-90. DOI: 10.46754/JSSM.2021.07.006

Ransaleleh TA, Maheswari RRA, Sugita P, Manalu W. 2013. Identifikasi kelelawar pemakan buah asal Sulawesi berdasarkan morfometri. J Veteriner 14 (4): 485-494. [Indonesian]

Ransaleleh TA, Maheswari RRA, Sugita P, Manalu W. 2014. Pendugaan produksi karkas dan daging kelelawar pemakan buah (Pteropus alecto) asal Sulawesi. J Veteriner 15 (1): 139-146. [Indonesian]

Ransaleleh TA, Nangoy MJ, Wahyuni I, Lomboan A, Koneri R, Saputro S, Pamungkas J, Latinne A. 2020. Identification of bats on traditional market in Dumoga District, North Sulawesi. IOP Conf Ser Earth Environ Sci 473: 1-7. DOI: 10.1088/1755-1315/473/1/012067.

Rocha R, Baucells AL, Llamazares AF. 2021. Ethnobiology of bats: Exploring human-bat Interrelationships in a rapidly changing world. J Ethnobiol 41 (1): 3-17. DOI: 10.2993/0278-0771-41.1.3.

Ruba E, Ransaleleh TA, Rumondor DBJ, Palar CKM, Rompis EG. 2016. Sifat organoleptik daging kelelawar dengan waktu pemasakan berbeda. Zootec 38 (2): 278-285. [Indonesian]

Scheffers BR, Corlett RT, Diesmos A, Laurance W. 2012. Local demand driver a bushmeat industry in a Philippine forest preserve. Trop Conserv Sci 5 (2): 133-141. DOI: 10.1177\%2F194008291200500203.

Schloesing E, Chambon R, Tran A, Choden K, Ravon S, Epstein JH, Hoem T, Furey N, Labadie M, Bourgarel M, De Nys HM, Caron A, Cappelle J. 2020. Patterns of foraging activity and fidelity in a Southeast Asian flying fox. Mov Ecol 8: 1-13. DOI: 10.1186/s40462020-00232-8.

Seltzer CE, Ndangalasi HJ, Cordeiro NJ. 2013. Seed dispersal in the dark: Shending light on the role of fruit bats in Africa. Biotropica 45 (4): 450-456. DOI: 10.1111/BTP.12029.

Sheherazade, Tsang SM 2015. Quantifying the bat bushmeat trade in North Sulawesi, Indonesia, with suggestions for conservation action Glob Ecol Conserv 3: 324-330. DOI: 10.1016/J.GECCO.2015.01.003.

Sritongchuay T, Hughes AC, Bumrungsri S. 2019. The role of bats in pollination networks is influenced by landscape structure. Glob Ecol Conserv 20: 1-13. DOI: 10.1016/J.GECCO.2019.E00702.

Suwannarong K, Schuler S. 2016. Bat consumption in Thailand. Infect Ecol Epidemiol 6: 1-5. DOI: 10.3402/IEE.V6.29941.

Suwannarong K, Balthip K, Kanthawee P et al. 2020. Bats and belief: A sequential qualitative study in Thailand. Heliyon 6: 1-9. DOI: 10.1016/J.HELIYON.2020.E04208.

Syamsi F. 2013. Tingkah laku siang hari Cynopterus sphinx. J Simbiosa 2 (1): 1-17. [Indonesian]

Ter-Hofstede HM and Fenton MB. 2005. Relationships between roost preferences, ectoparasite density, and grooming behaviour of neotropical bats. J Zool Lond 266 (4): 333-340. DOI: $10.1017 /$ S095283690500693x.

Tremlett CJ, Moore M, Chapman MA, Gutierrez VZ, Peh KSH. 2020. Pollinators by bats enhances both the quality and yield of a major cash crop in Mexico. J App Ecol 57: 450-459. DOI: 10.1111/13652664.13545.

Welbergen JA. 2006. Timing of the evening emergence from day roosts of the grey-headed flying fox, Pteropus poliocephalus: The effects of predation risk, foraging needs, and social context. Ecol Sociobiol 60: 311-322. DOI: 10.1007/S00265-006-0167-3.

Welbergen JA. 2008. Variation in twilight predicts the duration of the evening emergence of fruit bats from a mixed-species roost. Anim Behav 75: 1543-1550. DOI: 10.1016/J.ANBEHAV.2007.10.007.

Welbergen JA. 2011. Fit females and fat polygynous males: Seasonal body mass changes in the grey-headed flying fox. Oecologia 165: 629-637. DOI: 10.1007/S00442-010-1856-1. 